\title{
A insubmissão contra o gozo do pathos ou como desarmar a resistência do melancólico
}

Paulo José Carvalho da Silva

Este artigo analisa os típicos argumentos da resistência ao tratamento da melancolia tal como descritos nas técnicas terapêuticas difundidas pelo jesuíta francês Etienne Binet (15691639) em sua obra Consolation et réjouissance pour les malades et personnes affligés (1627).

Palavras-chave: Melancolia, resistência, gozo, pathos 
As primeiras investigações psicanalíticas indicavam que, nas neuroses, alguma representação ou correlativo afetivo do trauma permanece recalcado no inconsciente e os sintomas desempenham a função de expressão codificada do recalcado. Assim, o procedimento central do tratamento consistia na interpretação dessa relação, revelando em especial o que o simbolismo dos sintomas encobria ou deslocava. Como comenta Lacan a esse respeito, em "Les complexes familiaux dans la formation de l'individu" (1938), há nessa concepção otimista de cura psíquica um resquício da ideia socrática da cura pelo conhecimento de si por meio da razão: trazer à consciência a impressão na origem e demonstrar o caráter irracional do sintoma. Foi necessário retificar essa compreensão do tratamento psicanalítico na medida em que a experiência mostrou, entre outras coisas, que uma resistência à elucidação do sintoma é apresentada pelo sujeito.

Na verdade, Freud não demora a se dar conta da existência de múltiplas formas de resistência. Ele menciona o problema já na "Interpretação dos sonhos" (1900), em particular, no esquecimento ou nas alterações dos relatos dos sonhos. Mais tarde, nas "Lições introdutórias à psicanálise" (1916-1917), Freud afirma que dificilmente se encontra um paciente que não tenha tentado silenciar alguma parte de sua vida psíquica preservando-a da análise. Os obsessivos exageram seus escrúpulos e vacilações enquanto que os histéricos levam o procedimento ao absurdo, confessando apenas 
ideias, sentimentos e recordações que não têm relação com o que se busca. A resistência também pode assumir um caráter intelectual, com o uso de argumentos da literatura científica contra as teorias psicanalíticas.

Por outro lado, vale lembrar que a formação dos sintomas é análoga à formação dos sonhos, ambos cumprindo a função de reanimar uma sensação ou representar uma imagem fantasmática pertencente a um complexo sexual. Daí decorre que os sintomas não implicam apenas sofrimento. Tanto é que, em 1920, no "Além do princípio do prazer", Freud assume, como é bastante conhecido, que o neurótico não quer mudar, por mais aflito que esteja.

Por sua vez, os discursos e práticas terapêuticas do pathos psíquico disponíveis na primeira modernidade (séculos XVI e XVII), normalmente abordados nesta seção, eram essencialmente baseados naquele ideal socrático da cura pelo conhecimento de si por meio da razão. Ou ainda: cura pelo domínio sobre os desejos que o conhecimento de si por meio da razão permitiria. Isso os distingue radicalmente da nova medicina da alma freudiana, para a qual o império da razão será sempre precário e provisório. Por outro lado, os autores daqueles tempos mostravam-se muito atentos aos efeitos das paixões e já haviam notado que algumas pessoas apresentam todo um esforço de recusa de tratamento e de apego à própria enfermidade.

Esse gozo da enfermidade e resistência a falar sobre sua experiência eram particularmente observados nos casos diagnosticados como melancolia, em especial os chamados melancólicos hipocondríacos. Em Les consolations de la philosophie et de la théologie, René de Cerisiers (1603-1662), por exemplo, descreve os devaneios do melancólico que, declaradamente, goza de sua própria dor e recusa qualquer consolação: "As amarguras são minha alegria/ E eu temo intensamente ser feliz/Que os males mais rigorosos/Dividam meus dias de uma vez/ A dor, gemidos/ Todos esses piedosos alarmes/ Que nos fazem cair em pranto/ Dão-me ao me dar lágrimas/Ricas pérolas e flores" (1638, p. 1-2; trad. nossa).

Este artigo analisa, em particular, como esse fenômeno é tratado nas técnicas terapêuticas aplicadas ao melancólico por outro jesuíta francês, chamado Etienne Binet (1569-1639), em sua obra Consolation et réjouissance pour les malades et personnes affligés (1627), na qual há um capítulo inteiramente dedicado a desarmar os argumentos intelectuais do que poderíamos chamar de resistência do melancólico. 
Na primeira modernidade, toda sorte de literatura referia-se a melancólicos torturados por aflições interiores, imaginações e escrúpulos, supostamente causados pelo excesso de bile negra, um dos quatro principais líquidos corporais, conforme a medicina antiga hipocrático-galênica. Muitos autores identificavam melancolia e tristeza, tratando-as como um mal essencialmente moral. Outros ainda conjugavam categorias da chamada medicina humoral e das doutrinas sobre os afetos, de matriz propriamente aristotélico-tomista, sem, contudo, compactuar com a hipótese da soberania do temperamento do corpo (predominância de um humor) na determinação do caráter moral. Essa parece ter sido a posição tomada pelos pregadores e professores de filosofia e teologia da antiga Companhia de Jesus, como é o caso de Etienne Binet.

Naquela época, a antiga tradição filosófica da consolação impunha-se como uma das mais importantes modalidades de terapêutica da alma. Novas interpretações da tradição foram produzidas conforme as novas sínteses filosóficas das escolas de pensamento em vigor no período, bem como as orientações teológicas e identidades pastorais das ordens religiosas às quais os autores de textos de consolação pertenciam. Por exemplo, René de Cerisiers (1603-1662) retomou explicitamente a obra de Boécio (480?-525), A consolação da filosofia, e publicou, em 1638, o já citado diálogo chamado Les consolations de la philosophie et de la théologie, ao longo do qual o melancólico e atormentado "Celestin" é tratado pela personificação da Sabedoria, por meio de argumentos filosóficos e, sobretudo, preceitos teológicos.

Não saberíamos precisar até que ponto os diálogos publicados na época representam a prática real da consolação. Entretanto, ao compará-los com outros gêneros de manuais, guias e cartas de consolação, algumas instruções sobre o funcionamento ideal dessa conversa particular podem ser ressaltadas. De qualquer forma, esses diálogos eram concebidos para funcionar como instrução ou, como se afirmava na época, espelho no qual consoladores e pessoas em sofrimento podiam ver-se e, a partir disso, aprender como se dá o processo. Por exemplo, no Les visites charitables (1667), o influente calvinista Charles Drelincourt (15951669) explica que os diálogos de consolação por ele elaborados são pequenos quadros instrutivos que sintetizam sua experiência, adquirida durante 47 anos de prática, e que serviriam de referência aos consoladores iniciantes, algo comparável às coletâneas de estudos de casos clínicos para efeito de transmissão. 
Como a melancolia apresenta, na maioria das vezes, tristeza e temor, foram produzidos, na Idade Moderna, livros ou parte deles com objetivo de consolar os melancólicos. No próprio Les visites charitables (1667) de Charles Drelincourt, o primeiro diálogo entre o pastor consolador e o fiel aflito trata exatamente da melancolia. Outro exemplo, bastante conhecido, é o A treatise of melancholy do médico inglês Timothy Bright (1550?-1615), dedicado à consolação de um amigo, o melancólico M., cuja melancolia, segundo Bright, não apenas atingira os sentidos do corpo, mas penetrara mais fundo, na alma e no espírito. Assim, seu livro pretende, ao examinar as causas e discutir os remédios da melancolia, trazer algum conforto para o amigo ou, em suas palavras, “... alguma luz para a alma mergulhada na escura meia-noite da ignorância, distraída com dúvidas e desesperados pensamentos" (1586, dedicatória; trad. nossa).

\section{Um médico de almas provocador}

Etienne Binet nasceu em Dijon, em 1569, e parece ter feito seus estudos no Colégio de Clermont. Tornou-se jesuíta em 1590, assumindo cargos de responsabilidade dentro do ramo francês da Companhia de Jesus, além de ser professor, pregador e diretor espiritual. Morreu em Paris, em 1639.

A maior parte de sua extensa obra pertence ao gênero hagiográfico ou pastoral. Sobre a consolação dos aflitos e enfermos, Binet ainda escreveu o Consolation des âmes désolées et qui sont dans les aridités et abandonnements, publicada em Paris, em 1626, e o Remèdes souverains contre la peste et la mort soudaine, publicada pela primeira vez em Besançon, em 1628. Este último é um pequeno volume (207 páginas de $5 \mathrm{~cm}$ x $8 \mathrm{~cm}$ ) organizado não na forma de diálogo, mas por tipo de instrução para diferentes aspectos da peste, sobretudo, os afetivos, como o medo.

O Consolation et réjouissance foi publicado pela primeira vez em Pont-àMousson, na região da Lorraine, em 1617, recebendo logo novas edições. O livro é organizado na forma de um diálogo entre um consolador e um enfermo que, aliás, parece gozar de boa situação material e que possui considerável cultura religiosa e literária. O enfermo apresenta questões e problemas e, em seguida, recebe respostas que podem dar início a uma dinâmica de objeções e contra-argumentações. As respostas são, muitas vezes, complementadas com histórias exemplares de casos de cura bem sucedidas ou exemplos de paciência e fé dos 
santos e mesmo de figuras públicas, como aristocratas que deram provas de grande caráter.

Os temas abordados incluem o sentido espiritual das enfermidades, os princípios essenciais da arte da consolação cristã do enfermo de modo geral e, em casos específicos, tais como os enfermos de gota, de cegueira e surdez, os melancólicos e hipocondríacos, os febris, ou ainda os aflitos por causa do medo da morte, de imaginações desordenadas e dúvidas espirituais.

Em específico, o diálogo sobre a consolação da melancolia começa com a afirmação do melancólico de que a sua melancolia o mata. A resposta do consolador consiste justamente na mudança de posição de paciente para a de agente: ele aconselha que o melancólico a mate primeiro.

Binet é, antes de mais nada, um consolador espiritual e, como tal, propõe fortalecer a fé por meio das práticas de piedade enquanto medicina da alma para combater a melancolia. Entretanto, é interessante notar que aparece, em sua argumentação, logo de início, um ponto em comum com a medicina e com a filosofia, que é justamente procurar pela causa da melancolia para poder remediá-la. Ele sugere que o enfermo, ao empreender essa investigação, torne-se sujeito de seu próprio processo de cura, responsabilizando-se por ela, em vez de acomodar-se ao lugar de vítima, presa fácil da enfermidade.

Conforme a tradição antiga, o consolador deve propor o uso do logos para moderar o sofrimento. Em outros termos: usar da razão para examinar os seus fundamentos, o que, em geral, era feito colocando em dúvida o caráter natural e racional; ou da representação, ou do julgamento sobre o objeto suposto ameaçador e nocivo. Com isso, colocava-se a suposta causa da tristeza numa proporção, minimizando a sua dimensão. É exatamente o que faz Binet ao dizer ao melancólico que qualquer que seja o motivo de sua tristeza, ele (o motivo) não merece todo o crédito que o melancólico lhe confere. Assim, o remédio consiste em desprezar a melancolia.

Para não perder a tranquilidade, é necessário mostrar-se superior às paixões da alma, aos pesares, às palavras atravessadas, entre outros incômodos. É preciso reagir; sobretudo porque a melancolia subjuga principalmente os passivos e sonhadores, sempre condenados à disposição triste e ao silêncio morno.

O melancólico não se convence tão facilmente. Ele resiste e argumenta que sua disposição se deve ao seu humor: "O enfermo: o que se pode fazer? É meu humor, eu não posso refundir meu natural e me proporcionar um novo temperamento, eu me irrito comigo mesmo e não saberia dizer o quanto odeio a tristeza 
na qual vejo mergulhada minha vida e meus prazeres afogados, apesar de mim" (Binet, 1627, p. 93).

Em outras palavras: seu mergulho na tristeza é uma patologia do corpo, da natureza dominante de seu soma, uma realidade concreta e palpável. Seu argumento lembra muito o das pessoas que, apoiadas no discurso científico, se dizem portadoras de depressão, enquanto disfunção neurofisiológica, quase como se expressassem: "é meu corpo, não sou eu, não tenho nada com isso, estou doente".

$\mathrm{Na}$ época de Binet não se falava, evidentemente, de processos neurofisiológicos, mas de líquidos humorais para explicar a retração motora, afetiva e ideativa característica da melancolia. Mostrando que conhece a explicação médica vigente, o consolador admite que esses famigerados líquidos negros possam, de fato, entorpecer o corpo, abater o espírito, tornar sombrios os pensamentos e perturbar a imaginação. Entretanto, ele defende que não se deve adular o mal, sob pena de piorá-lo. Ao contrário, deve-se desprezá-lo, tratá-lo rudemente, o que permite aliviar-se e até mesmo mudar. Isto é, mesmo havendo um condicionante natural, ele não é totalmente determinante, há sempre a possibilidade de aderir ou não à tendência do temperamento melancólico. Inclusive, é preciso lembrar que, do ponto de vista filosófico-teológico, admitir o contrário feria um dos preceitos mais importantes do catolicismo contrarreformado: o livre-arbítrio.

O consolador recomenda, neste caso, uma insubmissão, uma rebeldia contra a natureza que, por mais feroz que se apresente, deverá ser domada. Ele defende a responsabilidade moral sobre o estado da alma desencadeado na melancolia, sem, com isso, negar os seus processos e condicionantes psicossomáticos:

Mas, se você bajular seu mal, você o piorará; se, pelo contrário, o maltratar, você o amenizará bastante e poderá até mesmo modificá-lo. Quando, por uma proeminência violenta, a melancolia escapa e se desenvolve, saindo de nós e nos surpreendendo, deixe-a correr, é uma louca, não corra atrás, o que está feito, está feito: mas abandonar-se voluntariamente, condenar-se por si mesmo, tornar-se escravo oferecendo suas mãos ao jugo é não saber ser homem. (Binet, 1627, p. 94)

O enfermo segue, porém, argumentando que se a compleição natural não justifica a infelicidade melancólica, as mazelas do mundo o fazem: enfermidades, misérias, perda dos amigos, tudo isso tem o poder de eclipsar a felicidade e impelir à melancolia. A origem está nos acontecimentos externos, alheios à sua vontade e capacidade de decisão. 
Mais uma vez, o consolador responde que tudo depende de como ele se coloca frente aos inexoráveis golpes da fortuna, como uma perda. Já se pensava, há muito tempo, que a melancolia está relacionada à impossibilidade do luto. Para Binet, bem como para o consolador da primeira modernidade em geral, em vez de chorar indefinidamente a perda de um amigo, o enlutado deve procurar novas amizades. Dito assim soa pouco empático e muito insensível à necessidade do trabalho de luto. No entanto, trata-se simplesmente de afirmar que, perante a irrupção da falta, mais cedo ou mais tarde, deve-se por a libido em movimento no lugar de deixar-se afetar tanto pela dor.

Este foco na relação simbólica com o real não apenas cria a possibilidade para o campo das psicoterapias de modo geral, como permite operar sobre os seus próprios entraves. Freud, em uma nota de 1925, ao capítulo VII de A interpretação dos sonhos, reconhece que acidentes externos a uma psicanálise e mesmo às intenções de um paciente podem acabar por levá-lo a interromper o processo. Todavia, ele adverte que a resistência manifesta-se, nesses casos, na forma como o paciente deixa-se afetar pelos acontecimentos e no emprego exagerado dos mesmos.

Independentemente dos mandamentos do corpo ou das condições do meio externo e das circunstâncias e acidentes da história da vida da pessoa, o que se pode efetivamente questionar e, no limite, modificar, é como essa pessoa se deixa afetar por tudo isso. Binet aposta no caráter decisivo da força da alma a ponto de afirmar como mais uma provocação ao melancólico que as almas fracas se entristecem por qualquer coisa, o espírito forte não se surpreende de nada.

Binet propõe uma disciplina da ação em oposição frontal à passividade, bem como à ociosidade, sobretudo, à ociosidade mental. Essa disciplina constitui-se de preceitos dietéticos antigos retomados pelos médicos da época e largamente difundidos. Não se deve pensar que se trata de uma apologia da mania como antídoto da melancolia. Longe disso: a grande chave dessa medicina é justamente a moderação, que convém ao ideal de Honnête homme, senhor de si e prudente, definido nos padrões de civilidade do Renascimento. Ideal esse provavelmente conhecido do leitor de Binet. Ele, na realidade, só faz lembrar que não é saudável, muito menos honroso, deixar-se dominar pela paixão sombria da tristeza, porque, afinal, é a razão que define a própria humanidade, distinguindo o homem dos animais considerados inferiores.

Apesar de diferenças radicais no que diz respeito aos ideais de cura, há na ética desse antigo tratamento algo muito próximo do que está em jogo na clínica 
psicanalítica. Do lado do paciente, padecer da paixão parece ser o denominador comum. Apesar do tom por vezes brutal, Binet mostra-se ciente do sofrimento que advém de ser atravessado pela paixão, movimento de fora, que chega sem avisar e sem ser convidado e que desestabiliza, faz sofrer. O que ele combate é justamente a submissão passiva e repetitiva do estado d'alma que daí decorre.

O tratamento segue uma dinâmica entre ser objeto da paixão e, portanto, adoecer e ser sujeito e rebelar-se contra a paixão, curando-se. É evidente que, no caso de Binet, bem como todos os médicos da alma da época, está em uso o pressuposto de que é não apenas desejável, mas perfeitamente possível, exercer um domínio, talvez não absoluto, porém, pelo menos, diplomático, dos próprios desejos.

Todavia, isso não significa uma completa ignorância do gozo humano. Pelo contrário, as provocações do consolador denunciam uma satisfação secundária ou algum tipo de ganho com a enfermidade quando ele acusa o melancólico de bajular, cortejar servilmente ou lisonjear seu próprio mal.

Ademais, o gozo era relacionado à aversão à palavra, marca crucial da definição do melancólico:

(...) um homem que não compreende aquilo que ele escuta, que não saberia descolar seus lábios por desprezo, lábios amotinados contra as palavras, homem que fala muito pouco, com remorso, sempre com meias-palavras e tão sombriamente que ninguém o compreende, nem deseja escutá-lo, tanto ele o faz de malgrado; diriam um fantasma atado a uma cadeira. (Binet, 162, p. 95)

Binet descreve um silêncio moroso, monótono, sem energia, abatido, triste. Enfim, onde impera a impossibilidade de pôr em palavras, sobressai o afeto e o adoecimento do corpo. A melancolia aproxima-se, assim, da hipocondria.

Se a atitude ética que se pede numa psicanálise é a da associação livre, lá no século XVII também se pedia para não se calar, condição para pensar e curar. Lacan, em "Télévision" (1973), comenta que o que geralmente se qualifica de depressão não passa de tristeza. Tristeza essa que, por sua vez, seria uma falta, uma covardia moral que se situa, em última instância, no pensamento. $\mathrm{O}$ afeto, ele prossegue, vem a um corpo, cujo próprio seria habitar a linguagem. Ele se pergunta se é esse pecado um grão de loucura ou um verdadeiro toque do real. Ora, não é nessa direção que apontam as provocações de Binet contra o gozo do pathos manifesto na melancolia? 


\section{Referências}

Binet, E. (1627). Consolation et réjouissance pour les malades et personnes affligés en forme de dialogue. Texte presenté par Claude Louis-Combet. Grenoble: Jérôme Millon, 1995.

. (1628). Remèdes souverains contre la peste et la mort soudaine. Grenoble:

Jérôme Millon, 1998.

Bright, T. A treatise of melancholy. Contayning the causes thereof, and reasons of the straunge effects it worketh in our minds and bodies : with the phisicke cure, and spirituall consolation for such as have thereto adjoyned afflicted conscience. The difference betwixt it, and melancholy, with diverse philosophicall discourses touching actions, and affections of soule, spirit and body. London: John Windet, 1586.

CERIZIERs, R. Les consolations de la philosophie et de la théologie. Lyon: Hugueton, 1657.

Drelincourt, C. Les visites charitables ou les consolations chrétiennes, pour toutes sortes des personnes afligées. Genève: Jean Antoine et Samuel de Tournes, 1667.

FReud, S. Die Traumdeuteung. In: Gesammelte Werke. Frankfurt am Main: Fischer Verlag, 1981. v. II/III.

. Vorlesung: Widerstand und Verdrängung. In: Gesammelte Werke. Frankfurt am Main: Fischer Verlag, 1981. v. XI, p. 296-312.

. Jenseits des Lustprinzips. In: Gesammelte Werke. Frankfurt am Main: Fischer Verlag, 1981. v. XIII, p. 1-69.

LACAN, J. (1938). Les complexes familiaux dans La formation de l'individu. Essai d'analyse d'une fonction em psychologie. In: Autres écrits. Paris: Éditions du Seuil, 2001. p. 23-84.

. (1973). Télévision. In: Autres écrits. Paris: Éditions du Seuil, 2001. p. 509-546.

\section{Resumos}

(La insumisión contra El goce del pathos o cómo desarmar La resistencia del melancólico)

Este artículo analiza los típicos argumentos de la resitencia al tratamiento de la melancolia tal como descriptos em las terapêuticas difundidas por el jesuíta francés 
Etienne Binet (1569-1639) en su obra Consolation et réjouissance pour lês malades et personnes affligés (1627).

Palabras claves: Melancolía, resistência, goce, pathos

(L'insoumission à la jouissance du pathos ou comment désarmer la résistance du mélancolique)

Cet article analyse les arguments les plus typiques de la résistance au traitement de la mélancolie tel comme envisagés dans les techniques thérapeutiques diffusés par le jésuite français Etienne Binet (1569-1639) dans l'ouvre Consolation et réjouissance pour les malades et personnes affligés (1627).

Mots clés: Mélancolie, résistance, jouissance, pathos

(The unsubmissiveness to the pathos enjoyment or how to disarm the melancholic's resistance)

This paper deals with the most typical arguments melancholic use to present when resisting to the treatment according to the therapeutic techniques reported by the French Jesuit Etienne Binet (1569-1639) in Consolation et réjouissance pour les malades et personnes affligés (1627).

Key words: Melancholy, resistance, satisfaction, pathos

Citação/Citation: Carvalho da Silva, P.J. A insubmissão contra o gozo do pathos ou como desarmar a resistência do melancólico. Revista Latinoamericana de Psicopatologia Fundamental, São Paulo, v. 13, n.1, p. 116-127, mar. 2010.

Editor do artigo/Editor: Prof. Dr. Paulo José Carvalho da Silva

Recebido/Received: 3.2.2010/2.3.2010

Aceito/Accepted: $10.2 .2010 / 2.10 .2010$

Copyright: () 2010 Associação Universitária de Pesquisa em Psicopatologia Fundamental/University Association for Research in Fundamental Psychopathology. Este é um artigo de livre acesso, que permite uso irrestrito, distribuição re reprodução em qualquer meio, desde que o autor e a fonte sejam citados/ This is an open-acess article, which permits unrestricted use, distribution, and reproduction in any madium, provided the original author and source are credited

Financiamento: Pesquisa financiada pela Fundação de Apoio à Pesquisa do Estado de São Paulo - FAPESP/ Research finded by the Fundation for Research Support of the State of Sao Paulo. 
Conflito de interesses: O autor declara que não há conflito de interesse/ The author declares that has no conflict of interest.

\section{Paulo José Carvalho da Silva}

Psicólogo; psicanalista; mestre em História da Ciência pela Pontifícia Universidade Católica de São Paulo - PUC-SP; doutor em Psicologia pela Universidade de São Paulo - USP (Ribeirão Preto, SP, Brasil); membro da Associação Universitária de Pesquisa em Psicopatologia Fundamental (São Paulo, SP, Brasil).

Rua Cajaíba, 15

05025-000 São Paulo, SP, Brasil

e-mail: paulojcs@hotmail.com 